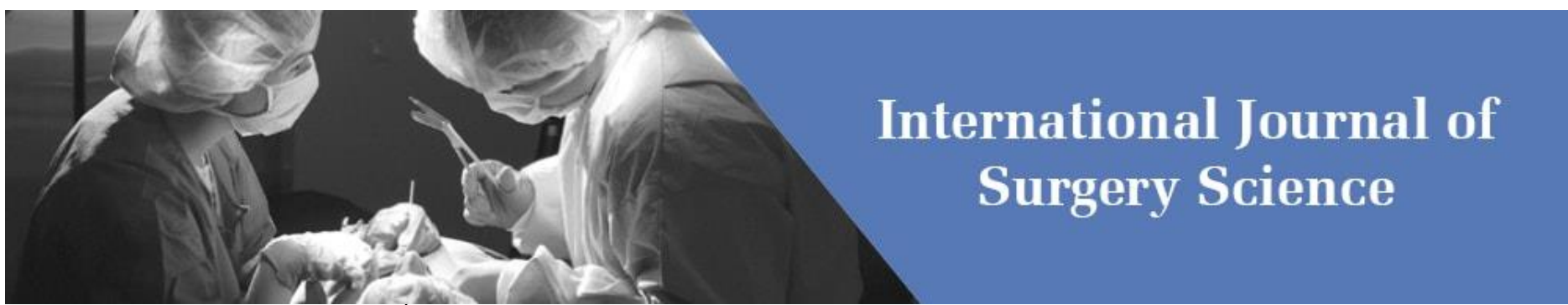

E-ISSN: 2616-3470

P-ISSN: 2616-3462

(C) Surgery Science

www.surgeryscience.com

$2019 ; 3(3): 344-348$

Received: 14-05-2019

Accepted: 18-06-2019

Dr. Khalid Jasim Daham

M.B.Ch.B. D.M, Al-Hakim general

hospital, Baghdad, Iraq

Dr. Kadhim Ismaiel Hamel

M.B. Ch.B. D.GS, Hakim general

hospital, Baghdad, Iraq

Dr. Sarmad Ahmed Khorsheed M.B.Ch.B. D.GS, Hakim general hospital, Baghdad, Iraq
Correspondence

Dr. Khalid Jasim Daham

M.B.Ch.B. D.M, Al-Hakim general

hospital, Baghdad, Iraq

\section{Management of ulcerative colitis in sample of Iraqi patients}

\section{Dr. Khalid Jasim Daham, Dr. Kadhim Ismaiel Hamel and Dr. Sarmad Ahmed Khorsheed}

DOI: https://doi.org/10.33545/surgery.2019.v3.i3f.192

\section{Abstract}

Background: Ulcerative Colitis (UC) is a chronic inflammatory disease involving the colon, with alternating periods of remission and activity. Exacerbations can be severe and associated with complications and mortality. Diagnosis of severe UC is based on clinical, biochemical and endoscopic variables.

Objective: To assess the management of ulcerative colitis.

Method: A descriptive cross-sectional study was carried out in the Al-Hakim general hospital, in the period between January 2015 and December 2018. The study was constituted by all the elderly patients of 19 years old and more, with a confirmed diagnosis of Ulcerative colitis that are admitted to the hospital. We studied 176 patients with UC who collected the inclusion criteria and accepted to participate in the study.

Results: The average of patients were $44.8 \pm 16.5$ years, female were dominant than male with $2: 1$ ratio. Regarding to the smoking $31(17.6 \%)$ patients were smokers and the rest $145(82.4 \%)$ were not. The oral administration of Sulfasalazine, Mesalazine and prednisolone were the most used. As a treatment adjuvant, the most commonly used medications were folic acid, vitamins, zinc sulfate, probiotics, iron and nutritional supplements.

Conclusion: The most frequent causes that motivated the surgical treatment were stenosis and colorectal cancer.

Keywords: Ulcerative colitis, Sulfasalazine, chronic inflammatory disease

\section{Introduction}

Ulcerative Colitis (UC) is a chronic inflammatory disease involving the colon, with alternating periods of remission and activity. Exacerbations can be severe and associated with complications and mortality. Diagnosis of severe UC is based on clinical, biochemical and endoscopic variables. Patients with severe UC must be hospitalized. First line therapy is the use of intravenous corticoids which achieve clinical remission in most patients. However, $25 \%$ of patients will be refractory to corticoids, situation that should be evaluated at the third day of therapy. In patients without response, cytomegalovirus infection must be rapidly ruled out to escalate to second line therapy with biological drugs or cyclosporine. Total colectomy must not be delayed if there is no response to second line therapy, if there is a contraindication for second line therapies or there are such as: mega colon, perforation or massive bleeding. An active management with quick escalation on therapy allows to reduce the prolonged exposure to corticoids, reduces colectomy rates and its perioperative complications ${ }^{[1]}$.

\section{Epidemiology}

The UC has a bimodal pattern of incidence, the highest incidence is between 15 and 30 years, and the second largest incidence is between 50 and 70 years ${ }^{[2]}$. There are no studies that demonstrate preference according to gender. Developed countries as the United States (USA) and the countries of northern Europe have the highest prevalence incidence of UC worldwide. According to different series, the incidence varies from 9 to 20 cases per 100,000 people per year in the USA and in Northern Europe It varies from 9.4 to 19.6 cases per 100,000 people-year [3].

The prevalence is 156 to 249 cases per 100,000 inhabitants in the US and in the north of Europe 
varies between 243 to 291 cases per 100,000 inhabitants ${ }^{[4]}$. The prevalence is lower in countries in development although it has been increasing. In Asia, the prevalence ranges from 5.3 to 63.6 per 100,000 inhabitants ${ }^{[5]}$. In Japan, prevalence is estimated at 64 / 100,000 inhabitants ${ }^{[6]}$.

\section{Risk factors}

The incidence has increased in countries who have adopted a lifestyle industrialized, which refers to places where measures have been taken to improve the global condition of health as vaccination, prevention of gastrointestinal diseases, processed foods, etc ${ }^{[7,8]}$. The previous suggests that factors environmental impacts can influence trigger the onset of the disease, where the improvement in the systems sanitary reduces infections gastrointestinal problems during childhood restricting the maturation of the system immune associated with the intestinal mucosa.

A. Genetic factors. The family history of IBD is the factor of most important independent risk, being older in close relatives degree affected. $5.7 \%-15.5 \%$ of the patients with UC have the antecedent of first-degree relatives with the same disease ${ }^{[9]}$.

B. Environmental factors. Previous gastrointestinal infections produced by Salmonella spp, Shigella spp, Campylobacter spp.

double the risk of producing subsequently $\mathrm{CU}$, which would indicate that acute infections gastrointestinal disorders would alter the micro colonic bacterial flora triggering the disease in people genetically predisposed ${ }^{[10]}$.

C. Protective factors. Appendectomy reduces the risk of develop ulcerative colitis by $69 \%$ (OR $0.31,95 \%$ CI 0.25 0.38) 11 .

\section{Pathophysiology}

The colonic epithelium is protected by a mucous layer which is the first physical protection barrier e immunological where it is synthesized antimicrobial peptides and separates physically the local immune cells and the luminal bacteria. In UC, sub types of mucin (Mucin 2) is diminished, in addition to having less narrow joints (Tight juction), without however, the mechanism by which triggers chronic inflammation is still uncertain. With respect to the bacterial microflora, plays an important role in the development of the disease since the break of the homeostatic balance between the system immune of the mucosa and the microflora bacterial results in a response altered the immune system against non-pathogenic commensal bacteria of the colon. Classically at the level of the blade own are present a lot of dendritic cells and macrophages the have a function of presentation of antigens to $\mathrm{T}$ lymphocytes and $\mathrm{B}$. The activity of dendritic cells is increased and the number of cells circulars correlate with the disease activity what would indicate an important role at the beginning and perpetuation of inflammation. The Dendritic cells express receptors of microbial recognition including the TLR (Toll-like receptors) ${ }^{[12,13]}$.

Table: Clinical characteristics of ulcerative colitis

\begin{tabular}{|c|}
\hline Diarrhea \\
\hline Hematochezia \\
\hline Abdominal pain \\
\hline Rectal tenesmus \\
\hline Rectal urgency \\
\hline Lose weight \\
\hline Ocular manifestations \\
\hline Scleritis, episcleritis and uveitis \\
\hline Dermatological manifestations \\
\hline Erythema nod sum, pyoderma gangrenous \\
\hline Musculoskeletal manifestations \\
\hline Arthropathies \\
\hline
\end{tabular}

\section{Diagnosis}

The diagnosis of UC is based on the compatible signs and symptoms, being the colonoscopy with biopsies Serials needed to confirm the diagnosis and assess accurately the extent and intensity of the disease ${ }^{[14]}$. For the diagnosis of UC It is essential to rule out other causes of diarrhea as infectious (Viral, bacterial, parasitic, fungal) and not Infectious (Mal absorption, bacterial overgrowth, cancer or induced by drugs, among others). Usually, inflammation begins in the rectum and advances uninterruptedly towards proximal, affecting part or all of the colon, however, in some patients with Proctitis or side commitment left colon can present a zone of inflammation at the level of cecal valve which is called " Cecal patch " and does not change the diagnosis to Crohn's disease ${ }^{[15]}$.

Table: Classification of Montreal (2006): According to URC location.

\begin{tabular}{|c|c|}
\hline Ulcerative rectocolitis-URC & Classification of Montreal \\
\hline E 1- Proctitis & Limited to rectum (30\%) \\
\hline E 2 - Left Sided Colitis & Affects the rectum and left colon (distal to the splenic flexure) (40\%) \\
\hline E 3 - Pancolitis & Affects the rectum and colon proximal to the splenic angle (30\%) \\
\hline
\end{tabular}

\section{Surgical treatment in colitis ulcerative}

The treatment of patients with ulcerative colitis is multidisciplinary, and mainly done by doctor. However, a 15$35 \%$ of patients will need some type of surgery ${ }^{[16]}$. The objectives major of the surgery are to alleviate symptoms, minimize the risk of cancer and offer a good quality of life to the patients ${ }^{[17]}$.

Indications for surgical procedure are divided into, emergencies and electives. Emergency surgery is performed in the patients with fulminant colitis that does not respond to medical treatment. Urgent in cases of patients with UC seriously admitted to the hospital that does not respond to intensive multidisciplinary medical treatment. Electives in case of refractoriness or intolerance to medical maintenance treatment and in cases of dysplasia or colorectal cancer ${ }^{[18]}$.

The choice of procedure depends on patient comorbidities, 
surgeon's experience or if it's surgery emergency or elective. In surgeries of emergency / urgency a subtotal colectomy, which consists of the removal of the entire colon and the preservation of the rectum, it is also performed a temporary ileostomy, since it must be avoid in the acute phase the construction of the Ileal Reservoir Surgery With Anal Reservoir Anastomosis (IRARA) due to the risk of failure of anastomosis, sepsis, nerve damage pelvic or pelvic hemorrhage. Once the patient has recovered from the acute phase (usually 6 months), will carry out the construction of the ileal reservoir surgery with anal reservoir anastomosis. For elective surgeries, what is preferred is the panproctocolectomy with IRARA where continuity is enteral maintained. The surgical technique consists of resection of the entire colon and straight, and then a reservoir is built distal ileal. For the ileal reservoir, described several confirmations (W, S, J), However, the most used currently is the configuration in "J" [19]. The reservoir joins the rectum anal area, using a reservoir anastomosis anal, which can be mechanical or manual, in the latter case the rectal mucosa closer to the margin anal. In this same surgery, the most frequent is that it is also built an ileostomy in a loop, which It will generally close after 3 months Associated adverse events are 30\% small bowel obstruction, pouchitis $26.8 \%$, fecal incontinence $14.3 \%$, pelvic sepsis $7.5 \%$ and is the most complicated, reservoir fistulas $4.5 \%, 3 \%$ sexual dysfunction, and infertility female with 3 times more risk ${ }^{[20]}$.

\section{Methods}

A descriptive cross-sectional study was carried out in the AlHakim general hospital, in the period between January 2015 and December 2018. The study was constituted by all the elderly patients of 19 years old and more, with a confirmed diagnosis of UC that are admitted to the hospital. We studied 176 patients with UC who collected the inclusion criteria and accepted to participate in the study. The variables studied were: age of diagnosis, sex, smoking habit, location of the disease, clinical manifestations, colonic and extra colonic complications, medications used, causes of surgical treatment and causes of death.

All the information was obtained from hospital or ambulatory histories, where the data was collected in a collection notebook. Statistical processing a database was created in Excel and the information was processed using the statistical package SPSS version 23. For the descriptive analysis of the data, frequency measurements were used absolute and relative, for qualitative variables.

\section{Results}

176 patients with UC were studied during the investigation period. The age of patients was range from 19 to 76 years, with an average of $44.8 \pm 16.5$ years, female were dominant than male with 2:1 ratio. Regarding to the smoking $31(17.6 \%)$ patients were smokers and the rest $145(82.4 \%)$ were not.

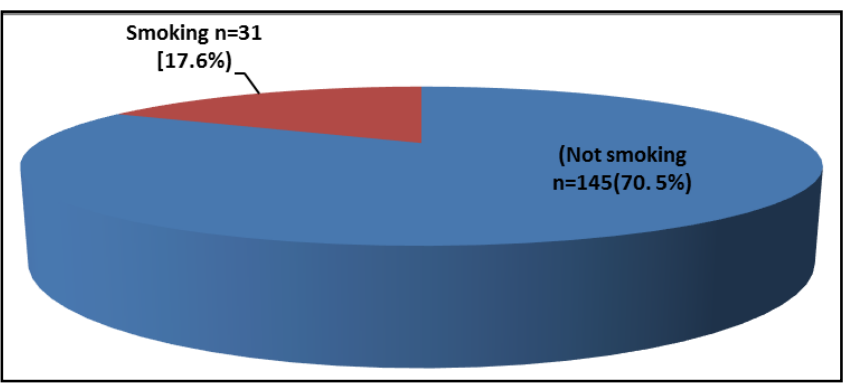

Fig 1: Distribution of patients according to the smoking.
The most frequent clinical manifestations were diarrhea, the expulsion of phlegm and rectal bleeding (Table 1).

Table 1: Clinical manifestation of the studied group $(n=176)$

\begin{tabular}{|c|c|c|}
\hline \multirow{2}{*}{ Clinical manifestations* } & \multicolumn{2}{|c|}{ UC } \\
\cline { 2 - 3 } & $\mathbf{N}$ & $\mathbf{\%}$ \\
\hline Diarrhea & 58 & 33.0 \\
\hline Phlegm & 60 & 34.1 \\
\hline Rectal bleeding & 44 & 25.0 \\
\hline Colic & 37 & 21.0 \\
\hline Abdominal pain & 32 & 18.2 \\
\hline Weight loss & 14 & 8.0 \\
\hline bowel incontinence with or without tenesmus & 36 & 20.5 \\
\hline Fever & 5 & 2.8 \\
\hline Abdominal distension & 25 & 14.2 \\
\hline Perianal lesion & 3 & 1.7 \\
\hline
\end{tabular}

*There were patients with more than one clinical manifestation

In relation to the medication treatment received, the oral administration of Sulfasalazine, Mesalazine and prednisolone were the most used. As a treatment adjuvant, the most commonly used medications were folic acid, vitamins, zinc sulfate, probiotics, iron and nutritional supplements (table 2).

Table 2: Medical treatment of the patients

\begin{tabular}{|c|c|c|}
\hline \multirow{2}{*}{ Medical treatment* } & \multicolumn{2}{|c|}{ Ulcerative colitis } \\
\cline { 2 - 3 } & $\mathbf{N}$ & \% \\
\hline Sulfasalazine oral & 113 & 64.2 \\
\hline Sulfasalazine enema & 3 & 1.7 \\
\hline Mesalazine oral & 53 & 30.1 \\
\hline Mesalazine enema & 1 & 0.6 \\
\hline Prednisolone oral & 20 & 11.4 \\
\hline Prednisolone IV & 2 & 1.1 \\
\hline Budesonide oral & 1 & 0.6 \\
\hline Hydrocortisone IV & 1 & 0.6 \\
\hline Azathioprin & 7 & 4.0 \\
\hline Methotrexate & 1 & 0.6 \\
\hline Infliximab & 2 & 1.1 \\
\hline Other medications** & 129 & 73.3 \\
\hline
\end{tabular}

*Patients may take more than one drug

**Other medications (Folic acid, vitamins, zinc sulfate, probiotics, iron and nutritional supplements, omega-3, Ursodeoxycholic acid, gamma globulin).

As seen in Figure 2, recto-sigmoid localization was predominant with 63 patients, followed by rectal (more distal) in 45 patients.

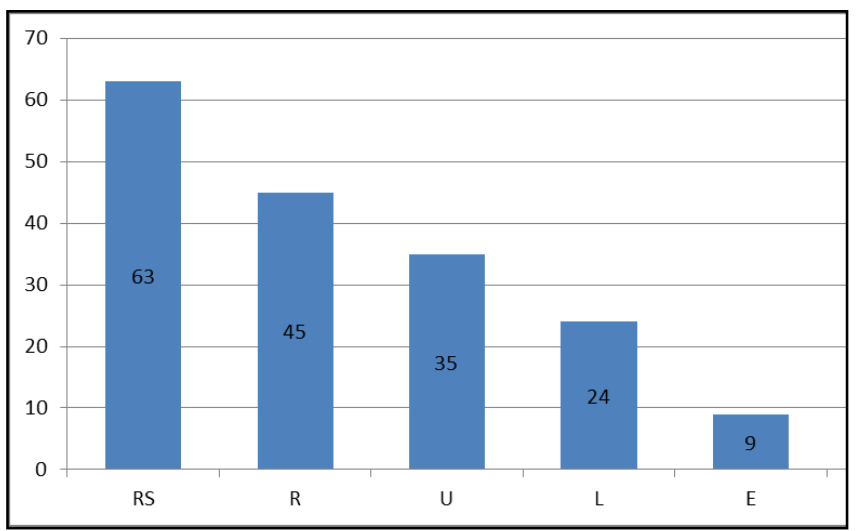

Fig 2: Distribution of the UC disease according to the site *RS=Recto-sigmoid, $\mathrm{R}=$ rectal, $\mathrm{U}=$ universal, $\mathrm{L}=\mathrm{left}, \mathrm{E}=$ extensive

As shown in Table 3, the most frequent causes that motivated the surgical treatment were stenosis and colorectal cancer, other 
causes which included the following: fistulas (Recto-vaginal, perianal), cholecystitis, and peritonitis.

The causes of mortality for UC were colorectal cancer (3 patients) and cholangio-carcinoma (2 patients).

Table 3: Distribution of the patients according to the causes of surgical treatment

\begin{tabular}{|c|c|c|}
\hline Causes of surgical treatment & $\mathbf{N}$ & $\mathbf{\%}$ \\
\hline Intestinal occlusion & 2 & 1.1 \\
\hline Stenosis & 25 & 14.2 \\
\hline Colorectal cancer & 3 & 1.7 \\
\hline Perforation & 1 & 0.6 \\
\hline Others & 30 & 17.1 \\
\hline
\end{tabular}

Others: Fistula (recto-vaginal, perianal), peritonitis, cholecystitis

\section{Discussion}

CD and UC are diseases of modern society and their frequency in developed countries has been increasing since the midtwentieth century, where these affect $2 \%$ of the world's population ${ }^{[16]}$.

When analyzing the mean age of diagnosis of UC, it was possible to find revised works, located in an age range between 30 and 40 years, the rate decreases with age and is fairly stable between the third and seventh decades of life. In the present study, the mean age of diagnosis was similar to what reported in Cosnes J et al study ${ }^{[17]}$.

Regarding sex, varied results were found, some studies, such as carried out in Spain, Denmark and Croatia and Lebanon, suggest that there is same proportion of patients for both sexes [18, 19], others report higher frequency for males, mainly in high incidence areas ${ }^{[20]}$. In the present study there was predominance of the female sex, in accordance with the results of the work carried out by Cosnes et al ${ }^{[17]}$, Thukkani and Sonnemberg ${ }^{[21]}$.

Regarding the relationship between smoking and $\mathrm{CU}$, what is found in this study corresponds to what is reported in the international literature because there was a predominance of non-smokers. However, there are authors like Roth et al ${ }^{[22]}$, and Bastida ${ }^{[23]}$ who report different results.

According to the extension of the UC, the most distal location (Rectum and sigmoid) was predominant in this study, which corresponds to what was reviewed in several studies ${ }^{[24,25]}$.

When analyzing the drug treatment used in the present study, it coincides with what raised in most of the articles reviewed, where the amino salicylates were the most used, in order of frequency, Sulfasalazine, Mesalazine, followed of oral steroids [26, 27]. Similar results were found in one study carried out in central China by Jiang and others ${ }^{[28]}$, the role of surgery in the treatment is increasingly better defined. In general, the main indications of surgical treatment in UC, are: failure of medical treatment, specific complications not resolved with medical treatment and to treat or prevent cancer or high-grade dysplasia [29].

In this study, the most frequent cause of surgery was stenosis, followed for colorectal cancer; result that is not in accordance with what was expected, that most of the literatures reviewed, including guides and consensus, raise to intra ability as the most frequent cause of surgical treatment and, In addition, it should be suspected that these colonic stenosis are malignant until to prove otherwise ${ }^{[30,11]}$. In this study, the frequency of cancer was lower than that reported in the previous studies ${ }^{[31,32]}$.

\section{Conclusion}

The most frequent causes that motivated the surgical treatment were stenosis and colorectal cancer.
The conflict of interest: there is no conflict of interest by the authors

\section{Source of funding: self}

Ethical clearance: was taken from the scientific committee of the Iraqi Ministry of health

\section{References}

1. Hernández-Rocha C, Ibáñez P, Molina ME, Klaassen J, Valenzuela A, Candia R. Diagnosis and management of ulcerative colitis. Rev Med chile. 2017; 145(1):96-105.

2. Loftus EV Jr, Sandborn WJ. Epidemiology of inflammatory bowel disease. Gastroenterol Clin North Am. 2002; 31:1-20.

3. Bernstein CN, Rawsthorne P, Cheang M, Blanchard JF. A population-based case control study of potential risk factors for IBD. Am J Gastroenterol. 2006; 101:993-1002.

4. Rubin GP, Hungin AP, Kelly PJ, Ling J. Infl ammatory bowel disease: epidemiology and management in an English general practice population. Aliment Pharmacol Ther. 2000; 14:1553-59.

5. Niriella MA, De Silva AP, Dayaratne AH, Ariyasinghe MH, Navarathne MM, Peiris RS et al. Prevalence of inflammatory bowel disease in two districts of Sri Lanka: a hospital based survey. BMC Gastroenterol. 2010; 10:32.

6. Asakura K, Nishiwaki Y, Inoue N, Hibi T, Watanabe M, Takebayashi T. Prevalence of ulcerative colitis and Crohn's disease in Japan. J Gastroenterol. 2009; 44:659-65.

7. Figueroa C, Quera R, Valenzuela J, Jensen B. Enfermedad Inflamatoria Intestinal: Experiencia de dos centros chilenos. Rev Méd Chile. 2005; 133:1295-304.

8. Moum B, Ekbom A. Epidemiology of inflammatory bowel disease-methodological considerations. Dig Liver Dis. 2002; 34:364-9.

9. Farmer RG, Michener WM, Mortimer EA. Studies of family history among patients with inflammatory bowel disease. Clin Gastroenterol. 1980; 9:271-7.

10. Garcia Rodriguez LA, Ruigomez A, Panes J. Acute gastroenteritis is followed by an increased risk of inflammatory bowel disease. Gastroenterology. 2006; 130:1588-94.

11. Koutroubakis IE. Appendectomy and the development of ulcerative colitis: results of a meta-analysis of published case-control studies. Am J Gastroenterol, 2000.

12. Hart AL, Al-Hassi HO, Rigby RJ et al. Characteristics of intestinal dendritic cells in inflammatory bowel diseases. Gastroenterology. 2005; 129:50-65.

13. Van Klinken BJ, Van der Wal JW, Einerhand AW, Buller HA, Dekker J. Sulphation and secretion of the predominant secretory human colonic mucin MUC2 in ulcerative colitis. Gut. 1999; 44:387-93.

14. Schroeder KW, Tremaine WJ, Ilstrup DM. Coated oral 5aminosalicylic acid therapy for mildly to moderately active ulcerative colitis. A randomized study. N Engl J Med. 1987; 317:1625-9.

15. Danese S, Fiorino G, Peyrin-Biroulet L, Lucenteforte E, Virgili G, Moja L et al. Biological agents for moderately to severely active ulcerative colitis: a systematic review and network meta-analysis. Annals of internal medicine. 2014; 160(10):704-11.

16. Danese S, Fiocchi C. Ulcerative colitis. N Engl J Med. 2011; 365:1713-25.

17. Cosnes J, Gower-Rousseau C, Seksik P, Cortot A. Epidemiology and natural history of inflammatory bowel 
diseases. Gastroenterol. 2011; 140:1785-94.

18. Molodecky NA, Soon IS, Rabi DM, Ghali WA, Ferris M, Chernoff $\mathrm{G}$, et al. Increasing incidence and prevalence of the inflammatory bowel diseases with time, systematic review. Gastroenterology. 2012; 142(1):46-54.

19. Jacobsen BA, Fallingborg J, Rasmussen HH. Increase in incidence and prevalence of inflammatory bowel disease in northern Denmark: A population-based study 1978-2002. Eur J Gastroenterol Hepatol. 2006; 8:601-06.

20. Loftus CG, Loftus Jr EV, Harmsen WS, Sandborn WJ. Update on the incidence and prevalence of Crohn's disease and ulcerative colitis in Olmsted County, Minnesota, 19402000. Inflamm Bowel Dis. 2007; 13:254-61.

21. Thukkani N, Sonnemberg A. Epidemiologic characteristics of patients with inflammatory bowel disease undergoing colonoscopy. Inflamm Bowel Dis. 2011; 17(6):1333-7.

22. Roth LS, Chande N, Ponich T, Roth ML, Gregor J. Predictors of disease severity in ulcerative colitis patients from South western Ontario. World J Gastroenterology. 2010; 16:232-6.

23. Bastida G. Smoking status in ulcerative colitis. World J Gastroent. 2011; 17(22):2740-7.

24. Sean K. Ulcerative colitis. A patient's Journey. BMJ. 2012; 344:2947.

25. Regueiro M, Rodemann J, Kevin E, Saul M, Swoger J, Baidoo L et al. Physician assessment of ulcerative colitis activity correlates poorly with endoscopic disease activity. Inflamm Bowel Dis. 2011; 17:1008-14.

26. Brakenhoff L, Heijde DMV, Homes DW. IBD and arthropathies: A practical approach to its diagnosis and management. Netherland. Gut. 2011; 60:1426-35.

27. Pithadia AB, Jain S. Treatment of inflammatory bowel disease. Pharmacological Reports. India. 2011; 63:629-42.

28. Jiang L, Xia B, Li J, Ye M, Yan W, Deng C et al. Retrospective survey of 452 patients with inflammatory bowel disease in Wuhan city, central China. Inflamm Bowel Dis. 2006; 12:212-7.

29. García H, Marina O, Andrade Gomes S, Villa Jiménez OM, González Fabian L, Wood Rodríguez L. Characterization of patients with ulcerative colitis treated at a tertiary level center. Cuban Journal of Medicine. 2016; 55(1):0-0.

30. García Betanzos R. Inflammatory bowel disease. Clinical Guidelines 2007; 7(27):24-40.

31. Rungo $\mathrm{C}$, Jess $\mathrm{T}$. Important changes in the pattern of colorectal cancer in patients with inflammatory bowel disease. Colorect. Cancer. 2013; 2(1):5-7. 